\title{
How can we consume new products ? The example of exotic foods (1930-2000)
}

\author{
Régnier F. \\ INRA, Consumption Research Laboratory \\ 65, boulevard de Brandebourg, 94205 Ivry-sur-Seine cedex, France \\ Faustine.Regnier@ivry.inra.fr
}

\begin{abstract}
How can we consume new products? This presentation is based on the example of exotic foods and on the detailed analysis of 9758 recipes from 4 German and French magazines, between 1930's and 2000. Magazines play an important role in taste diffusion, and they are a precious data source fort studying domestic and daily cooking and its transformations. The first point concerns the definition and the characteristics of "exoticism (order list of foreign recipes in France and Germany, evolutions through time) and it highlights the historical and sociological context of the interest of the diffusion of exotic foods, and the relationship between taste for exoticism and history of gastronomy, colonisation, immigrations streams and tourism, revealing national models. The second point examines the reactions toward culinary novelty: fear as well as seduction. We describe the various processes which encourage to consume new products (selection of products and dishes which are similar to the national tastes, importance of promoters), and we show that, in the same time, foreign recipes are seducing because of their difference with our food habits (they make us travel during a dinner, they are said to be good for health). In consequence exotic foods are a way to improve national cooking and national food habits.

Keywords : food - recipes - exotic - women's magazines - codification - seduction - culinary novelty

In order to understand how and why the culinary innovation is integrated into the French cooking, this contribution is based on the example of culinary exoticism in France and Germany, between the 1930s to the end of the 1990s (Régnier, 2004). This research has analysed a corpus of 9,758 cooking recipes taken from four women's magazines - Marie Claire and Modes et Travaux, published in France, and Brigitte and Burda, published in Germany. Women's magazines are not particularly well considered among the objects of research whereas they constitute a particularly rich data source. Indeed, women's magazines were selected because of the important role played by media in taste diffusion (Besnard and Grange, 1993; Warde, 1997) : magazines are at the origin of fashions as well as they reflect these fashions (see also Bourdieu, 1984). Moreover, women's magazines are a precious data source for studying domestic and daily cooking and its transformations. Indeed, a particular cooking is here studied: the one we cook and consume at home (and not the one we discover at the restaurant). Modes et Travaux and Marie Claire, Brigitte and Burda were selected because they have existed for a long time, because of their very wide circulation (they belong to the most widely read magazines in France and Germany), and because of their differences. The readers of Marie Claire and Brigitte live in urban country, although the readers of Modes et Travaux and Burda live in rural country. Consequently, they were collected in order to compare social distinctions between countries and between periodicals.
\end{abstract}


Each edition of the four magazines since their creation until the present day was analysed: 3,830 issues were systematically surveyed. My analysis included to points of view. On the one hand, a quantitative and statistical analysis, which concerns the importance of each type of exoticism and its diffusion. On the other hand, I focused on discourses (recipes and magazines commentaries about those recipes). It was a classical analysis of contents and also a work I realised with special software of textual analysis, Hyperbase, which could be used in French language as well as in German.

The French interest for the foreign products and dishes is ancient, but "exoticism" itself is much more recent: we have to wait until the beginning of the 20th century to see the terms " exoticism " and " exotic " to appear in the French culinary books (Régnier, 2004). For as much, the consumption of unknown products is not evident : those products may frighten because their consumption supposes a very closed contact. By buying, preparing and eating foreign products, a person incorporates something strange. The consumer introduces deeply in his body a foreign thing, abolishing in consequence the border between itself and what is still unknown. Aliments, first of all, can be regarded as dangerous, which is related to the fear of incorporation all the more strong as the food is new (Fischler, 1990; Augé, 1986). Moreover, the cook does not know the ways of preparing or of consuming exotic products. Foreign food habits may disgust when they suppose the use of non edible aliments in the culinary system of the consumer. For example, the consumption of raw fish, popular in the Japanese cooking, has been very strange for a long time in France and Germany. Lastly, a foreign way of cooking risks, more deeply, upset the traditional culinary system. However the respect of these traditions is the respect of an " order of the world " (Certeau, 1994, p.253), the one of the consumer. The exotic food and dishes- which mix for example sweetened and salted flavours - could then upset the traditional systems of food classification.

Consequently, we will here highlight the historical and social context which supported the diffusion of new culinary practices (1). Then, we will stress on the reactions concerning culinary innovation : process of selection allowing a consumer to eat new products (2), and in the same time desire of new foods and of different dishes (3).

\section{Historical and social context}

\section{a) Rankings and diffusion of exotic foods}

Below we have the classification of the 9,758 recipes by geographical area in order of number of recipes.

1 - Number of exotic recipes in the French and German magazines sampled 


\begin{tabular}{|c|c|c|c|c|}
\hline & \multicolumn{2}{|l|}{ France } & \multicolumn{2}{|c|}{ Germany } \\
\hline Exoticism & Number of recipes & & \begin{tabular}{|l} 
Number of recipes \\
\end{tabular} & \\
\hline Southern Europe & 749 & $8.3 \%$ & 2213 & $1.1 \%$ \\
\hline Distant islands & 277 & $0.5 \%$ & 58 & $.8 \%$ \\
\hline Western Europe & 206 & $.8 \%$ & 1408 & $9.8 \%$ \\
\hline $\begin{array}{l}\text { Recipes based upon } \\
\text { exotic fruit }\end{array}$ & 202 & $.6 \%$ & 655 & $.2 \%$ \\
\hline United States & 135 & $.1 \%$ & 210 & $.0 \%$ \\
\hline Mixed exoticisms & 133 & $.0 \%$ & 264 & $.7 \%$ \\
\hline India & 132 & $.0 \%$ & 341 & $.8 \%$ \\
\hline Far East & 129 & $.9 \%$ & 421 & $.9 \%$ \\
\hline Middle East & 125 & $.7 \%$ & 149 & $.1 \%$ \\
\hline Eastern Europe & 113 & $.3 \%$ & 600 & $.4 \%$ \\
\hline Northern Africa & 103 & $.9 \%$ & 30 & $.4 \%$ \\
\hline Latin America & 88 & $.3 \%$ & 138 & $.9 \%$ \\
\hline $\begin{array}{l}\text { Recipes based upon } \\
\text { spices }\end{array}$ & 80 & $.0 \%$ & 154 & $.2 \%$ \\
\hline Scandinavia & 69 & $.6 \%$ & 279 & $.9 \%$ \\
\hline Exotic & 53 & $.0 \%$ & 108 & $.5 \%$ \\
\hline Tropics & 18 & $.7 \%$ & 6 & $.1 \%$ \\
\hline Subsaharan Africa & 17 & $.6 \%$ & 5 & $.1 \%$ \\
\hline Indonesia & 17 & $.6 \%$ & 73 & $.0 \%$ \\
\hline Total & 2646 & $00.0 \%$ & 7112 & $00.0 \%$ \\
\hline
\end{tabular}

France and Germany have several points in common. In France and Germany, Southern Europe is the most frequent exoticism, more than $60 \%$ of which is composed of Italian recipes. We can also note a similar high frequency of exoticism from Western Europe as well as the low position occupied by Subsaharan Africa.

However, several differences appear very clearly in the percentages of exoticisms. In particular, Western European exoticism composes only $7.8 \%$ of exotic recipes in France but $19.8 \%$ in Germany. This can be accounted for by the large number of recipes of French exoticism in Germany (55\% of recipes of Western Europe exoticism in German magazines whereas recipes of German exoticism in French magazines make up only 13\% of Western European exoticism). The fact remains that the German magazines are much more interested 
in the forms of cuisine of neighboring European countries. Thus, the figures for exoticisms considered close by, either from a geographical or cultural point of view (Southern Europe, Western Europe, United States, Eastern Europe and Scandinavia) are much higher in Germany (66.2\% of exotic recipes) than in France (48.1\%). France, on the other hand, attaches a much greater importance to the forms of cuisine of countries farther away, such as those of the Northern Africa and the Middle East, whereas these exoticisms are negligible in Germany (Régnier, 2003).

In other words, the exotic foods specific to France are those of distant islands, Northern Africa and, to a lesser extent, Subsaharan Africa and the Tropics, that is to say exotic foods coming from former colonies.

The diffusion of exotics foods through time highlights other national particularities. Throughout the period, the proportion of exotic recipes in relation to the total number of recipes - exotic and national - is higher in the German magazines than in the French magazines. This suggests a much greater interest in Germany in the discovery of foreign culinary practices.

2 - Proportion of exotic recipes in relation to total number of recipes (\% per period of 10 years) in the French and German magazines sampled

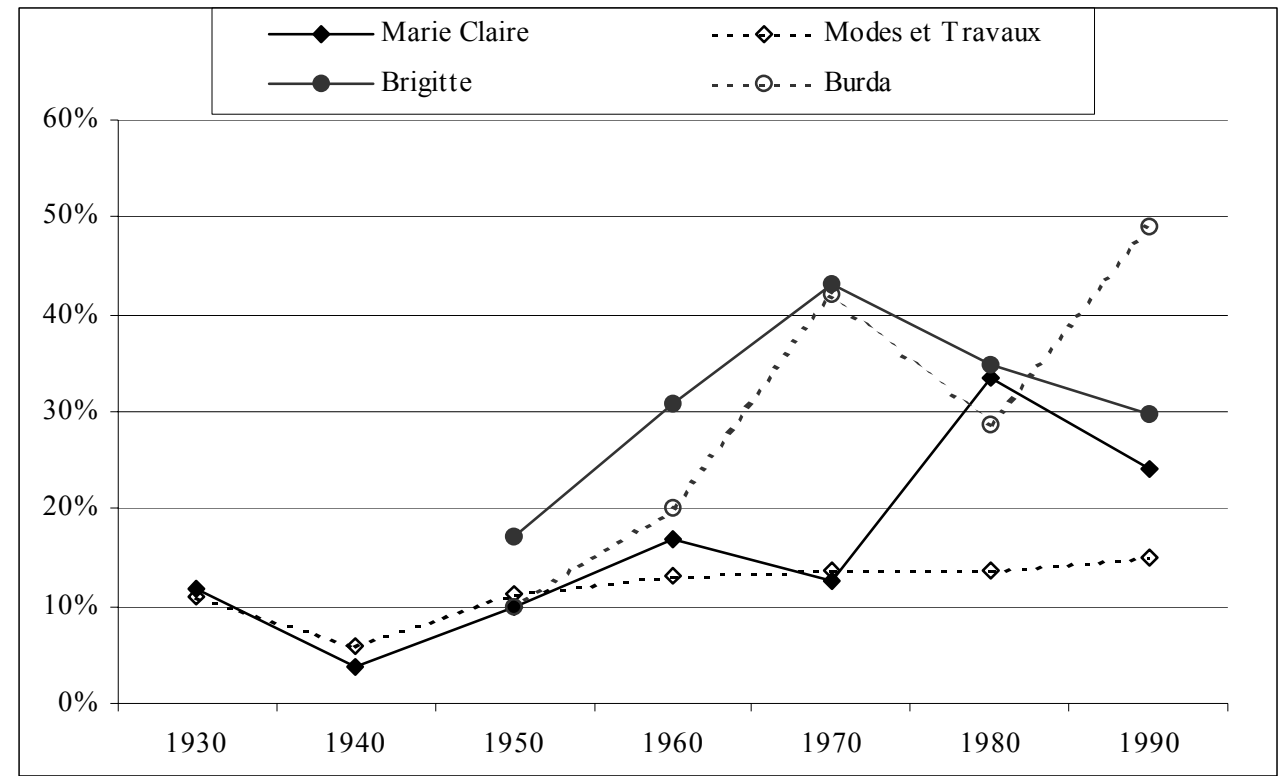

Interest in exoticism is very strong in the German magazines up until the 1970s: after the 2nd World War, Germany was very open to exotic cuisine. This proportion diminishes in the 1980s , although Burda found a new taste for exoticism in the 1990s. In France, the diffusion of exotic recipes displayed a more stable profile if one excludes the 1980s in Marie Claire where the proportion of exotic recipes is particularly notable. Modes et Travaux throughout its history is particular for its low proportion of exotic recipes.

\section{b) History of gastronomy}

The stability of the diffusion of exotic foods in France and, to the contrary, the strong interest in Germany after World War II can partly be explained by the differences concerning the history of gastronomy. The early establishment of the state with a strong royal court and centralisation in France at the end of the 17th century has been the framework for the formation of a high-standard cuisine in which there is an established interest ("taste") for foreign cuisines and foodstuffs (Elias, 1939a, 1939b ; Mennell, 1987). For some historians, the French interest for foreign food habits would even be older, dating from the Crusades 
(Ketcham Wheaton, 1984). This borrowing from foreign cuisine, which can be observed since the first major works of French cooking, is linked, in the large part, to the numerous voyages of French cooks abroad for work and pleasure, for example Vincent La Chapelle at the beginning of the 18th century, who travelled in England, in the Netherlands, in Portugal and even may be in the West Indies, or Antonin Carême at the beginning of the 19th century who travelled in England, in Russia and in many the other courts of Europe (Carême, 1833). They transformed and enriched the French art of cookery with foreign products and way of cooking they discovered out of France.

This former interest could explain the much slower and more stable diffusion of exotic recipes in the French magazines of the 20th century. The strong interest in exotic cuisine in Germany after World War II can be explained by the amplification and diversification of alimentary produce in the 1950s following years of privation and misery. Germany had experienced years of inflation, unemployment, economic crisis, the disappearance of many foodstuffs, and in particular imported foodstuffs, and the hunger and privations of the 2nd World War and the years just afterwards. The following years in which alimentary produce once more became accessible saw unrestrained alimentary consumption (Wildt, 1996).

The diffusion of the exotic food during the 20th century is moreover related to three fields, those where one is in contact with the foreign people : colonization, immigration and tourism.

\section{c) The influence of colonisation}

The colonial history of France can explain the high frequency of distant exoticism in French magazines. The French colonial expansion was long and extensive; it was accompanied by a large increase in the importation of alimentary products to mainland France - we find in the composition of several exotic foods the heritage of these flows which maintained the taste for exoticism - and the establishment of a large number of representations which were commonly expressed, for example, during the colonial and universal exhibitions which took place at the end of the 19th and the start of the 20th centuries (see Capatti, 1989 ; Hassoun and Raulin, 1995). This clearly accounts for the specificity of the exoticisms of Northern Africa and the Antilles in France, developed at the time of the colonial expansion. The German colonial expansion was, by comparison, much more limited in space and time, which can explain the smaller representation of distant exoticisms in Germany.

The decolonization, and particularly the wars of decolonization, had also an influence in the diffusion of the exotic products in France: the disappearance of Algerian exoticism in France takes place at the time of the war of Algeria, and the time of the war in Indo-China coincides with a very low number of Asian recipes. In time of war, foreign foods are not attracting anymore, which proofs that an unknown product is consumed only if it is perceived in a positive way, which is not the case when it is the food of our enemy.

\section{d) Immigration streams and prestige}

Colonization also was at the origin of migratory flows. Some can be at the origin of the thorough integration of foreign products. The interest in Asian forms of exoticism can be explained to a greater degree by migratory patterns, especially with the arrival of refugees from Vietnam in the 1970s. The economic activity of the Asian community is characterised by the importance of the alimentary sector. The restaurant sector is the most visible and wellknown part of Asian commerce. Furthermore, these Asian groceries and restaurants are "exotic": they were devoted to French (or German) customers, searching typical Asian dishes. In such a situation these restaurants constitute an important factor in the diffusion of Asian 
exoticism. The restaurants can cater to a less affluent or family clientele; such accessibility and openness favours the diffusion of Asian exoticism (Ma Mung et Simon, 1990).

But the relations between immigration and culinary exoticism are most of the time difficult to establish. For example, North Africans are the biggest foreign community in France, whereas the North African recipes account for $3,4 \%$ only of the whole exotic recipes in the French magazines, a fact related to various factors. First of all, North Africans in France have proximity shops, and they do not sell exotic products. In addition, this weak correlation between demographic importance of an immigrant population and culinary exoticism is related to the ambivalent status of the immigrant: Immigrants are generally in marginal economic activities - they face more unemployment, more flexible and less paid job. Those images of the poor worker are without prestige, which are not compatible with the deployment of culinary exoticism. Moreover, in situation of migration, the too strong proximity of the immigrants makes that the dream of exoticism cannot be developed any more. In order to consume foreign foods, it is necessary that foreigners remain a little distant and mysterious. When foreigners are too close, the differences are exacerbated and are perceived negatively.

One can thus underline a significant relation between consumption of new products and prestige. As J.-L. Flandrin (1995) shows, certain exotic products are rapidly adopted in the domain of the adoption of alimentary innovation if they replace traditional indigenous produce. More importantly, Flandrin emphasises that a foreign product can be easily introduced when it confers symbolic benefits or if it carries a connotation of prestige: "For a foreign foodstuff to be adopted its mere presence is not sufficient, other conditions must be fulfilled. It must be known that it is appreciated by a socially superior group or population of prestige such as the Italians during the Renaissance" (Flandrin, 1989, p.97). In this context, the movement of a foreign elite was at the origin of this strong taste for exoticism. It was the arrival of White Russians in Paris that explains the vogue for the exoticism of Eastern Europe in France, fleeing the Russian Revolution.

Consequently, culinary exoticism is particularly sensitive to prestigious events, for example the Olympic Games or the marriages of the royal families of the planet.

\section{e) Tourism and gastronomic discovery}

On the contrary, we can point out strong equivalences between tourism and exoticism. The most visited places also coincide with the most significant exotic foods (South Europe and Western Europe in particular). The contrary is also true : for example Black Africa, which still is few visited and whose exoticism is poorly represented in the four magazines. Tourism constitutes doubtless a mode of discovered products, unknown dishes, which one discovers on holiday, and which one then seeks to cook at home.

The more recent fashion for Italian cuisine and the other forms of cuisine from Southern Europe rely on the influence of tourism in this area. Thus, Southern Europe, which is distinguished in exoticism by its high occurrence, is also the most popular area in the world for tourism and a link between the development of tourism in the Mediterranean and a developing taste for the cuisine of this region is quite clear. Tourism explains to a large extent the success of Southern Europe dishes : Southern Europe constitutes at the same time the most familiar and the nearest place where one can find new savours, new products he is not used to eat.

However, it should be noted that Germany has a longer and more important history of foreign tourism than France. In the 1990s, the level of foreign departures was $60 \%$ for Germany compared with only $16 \%$ for France. Thus, tourism is a more relevant factor in Germany than in France ; German magazines regularly refer to tourism and holidays from the 
1970s onwards If immigration relates to the arrival from abroad at home, tourism returns to the even - illusory search - of remote horizons and other cultures. The bonds are marked between tourism and culinary exoticism: the exotic foods most usually quoted correspond to the principal tourist destinations.

\section{Foreign food are like ours}

\section{a) Substitution strategies}

In order to consume foreign foods and to integrate new products into the French (or German) cooking, various processes exist. These processes seek to replace these unknown practices within the familiar food habits. Culinary speaking, many processes rely on the substitution, which is based on the analogy between exotic and autochthon products. The substitution has to different meanings : the first one, is when local products take the place of some exotic products in exotic recipes. For exemple Marie Claire proposes in the first WestIndian recipe, acras, made originally with " vegetable roots which do not exist under our climates " $(38,19 / 11 / 37$, p.46) - the magazines mentions the yam or sweet potato, still badly known at the time - that one can replace by Jerusalem artichokes. Substitution, in this case, is certainly related to the difficulty of getting still rare products, but it is also a manner of making a French dish from an unknown dish. Substitution also consists of the introduction of an exotic product in a French or a German traditional recipe. Marie Claire proposes a " exotic flognarde " $(257,01 / 74$, p.75): a French, rustic and traditional dessert, the flognarde, is cooked with an exotic product, the banana.

\section{b) Conformity to our tastes}

To integrate the innovation, magazines also must underline that the foreign culinary practices are close to the national culinary practices. Culinary exoticism relies indeed on the search for its proximity with the national food practices and tastes, through an adaptation to these national tastes. Thus we select among exotic foods what is similar to our habits. Exoticism can then be used to adapt to typically French or German food. Parallels with the French or German cooking are often made in the magazines to underline the proximity of the exotic foods. Magazines mention a proximity of savours or of products, and sometimes it is simply a proximity in the speech which seeks to explain a foreign recipe through a comparison with our practices. Moreover, magazines try to classify and insert, within familiar food habits, unknown plants, products, animals, and to replace them within the French or German culinary culture, in order to preserve a familiar classifying system and to make familiar a culinary practice which seems strange and to explain it by culinary analogies. A magazine will employ for example the evangelic expression concerning couscous, which is known as " the daily bread of North Africa " (8, 01/04/98, p.226).

In consequence, the same exotic cooking is constructed differently in France and Germany. Thus Chily con carne is a marker of Mexican food in the two countries, but it does not refer to the same dish. In France, it is always a meat stew, with beans, tomatoes and chilli powder, that is to say the combination of meat and leguminous plant you have in many other French dishes (for instance lentils and morteau sausage). In Germany, the dish refers to something else, mainly meat balls with red beans sauce, tomatoes and chilli powder : you have here a typical German way of cooking, because meat balls are a really traditional German dish.

This selection of what is most similar to the national culinary practices explains, in very large part, the success of Spanish exoticism in Germany. Indeed, the first marker of this 
exotic food in the German magazines is the term " tapas ", these numerous small dishes consumed in Spain with aperitif while waiting for the evening meal. And tapas perfectly fit with a German way of eating, the Abendbrot. Abendbrot is the German dinner, which is much simpler than in France : it is most often composed of salad, bread and varied delicatessen and cheeses. Well tapas in Germany became a real dinner and they represent a variant of Abendbrot.

\section{c) Codification of exotic foods}

Within this framework, the development of exoticism consists in the reduction and the recombining of foreign culinary practices. This reconstruction is not due to hazard : it refers to a logic of synecdoque, this rhetorical figure which makes it possible to express a whole by one of its parts. Here, exoticism relies on the use of only one exotic product which transforms a whole classical recipe into an exotic one : a slide of pineapple makes from a traditional recipe an Hawaiian one. .Thus, one " hawaïen toast " is a toast with a slice of pineapple. The reduction of exoticism hawaiien to pineapple rests on the history of the food industry: it is in the Hawaii islands that the first attempts at preserve setting took place of pineapple, in the years 1880. It is in Hawaii also that at the beginning of the 20th century was developed the first machine of canning facility; from this date, tinned pineapples of Hawaii are produced with the chain and are diffused by large American firms in the whole world, in particular in Europe where they were successful (Péhaut, 1996).

Exoticism also relies on the recombining of foreign culinary practices around associations of products, but associations which remain in conformity with the national tastes, for example the banana and rum in West-Indian exoticism, whereas in Germany the banana is associated generally with salted products - for example with ham and cheese in a " toast with banana " - in a country where the distinction between sweetened and salted savours is less strong than in France.

\section{d) The importance of promoters}

Even if they are at the origin of fashions, magazines also mention various promoters who help to introduce the culinary innovation. Thus Marie Claire, who is a very Parisian and very aware of fashion magazine, introduces culinary exoticism through cinema stars. Thus, the first Japanese recipes are introduced in May 1965 by the actress Odette Laure whose cook is Japanese. Stars can thus appear, in this mechanism of diffusion of the exotic food, like true innovators. Moreover, they legitimate culinary innovation, which is related to their high social status, in a country (France) where gastronomy is closely related to prestige. Modes and Work more often refers to the medical discourse used as a guarantee: it makes it possible to introduce, with less fear, new products because the medical arguments justify the use of exotic products. Doctors authorize the pleasure of their consumption. These some lines on the exotic fruits, coming from the heading " the corner of the doctor ", clearly illustrates it : " They solve our problem dietetic of winter and preserve our health (...) They constitute authentic (and pleasant) drugs. Aperitifs, they stimulate digestive secretions. Eupeptiques, they support digestion at the people with the lazy stomach. Soft and refreshing laxatives, they activate secretions, then the motricity of the intestine, in the event of constipation by lifelessness " (Modes and Work 708, 12/59, p.109).

We also can see, through magazines discourses on exotic food, that the first reaction concerning new products aim at affirming the proximity of the exotic food with the national foods ; they codify the foreign culinary practices, which are transformed in order to be more similar to the national practices. But at the same time the curiosity, the research of new, the 
desire of variety and especially the seduction of the difference lead consumers to go beyond their fear of the unknown.

\section{The seduction of foreign foods}

\section{a) Desire of new products}

Two attitudes constitute indeed what $\mathrm{C}$ Fischler calls " the paradox of the homnivore ": fear and the need for the innovation, or " néophobie " and " néophilie " (Fischler, 1990). We also find in women's magazines discourses valorising the difference of exotic foods compared to the French or the German foods. Much more, the origin of the seduction of exotic products relies on this difference. Consuming exotic foods mean consuming charming and strange products, unexpected savours, coloured dishes, new way of cooking. This is why, while being made in conformity with the French or German food habits, the foreign culinary practices must remain a little mysterious: «Magic of the perfumes, savours and colours, the spices will blow on your kitchen a wind of exoticism, mystery and wonders " (Modes and Work 1042, 09/87, p.166). In consequence, foreign foods are better than ours and here is all the singularity of exoticism (Todorov, 1982).

Exotic foods are opposed to our daily and familiar food practices . Exotic foods appear to be in opposition to our common habits. In consuming exotic foods, it is possible to vary the daily habits, to fight against boredom or to renew the tradition. In this respect, the discourses of the magazines are often eloquent: " I very often noted that one wearied oneself to see appearing on the table of family, with a regularity full with monotony, dishes, always the same ones, according to the days of the week. I decided thus to renew my menus and sought in my notebooks foreign and exotic recipes which will bring an original note to the meals " (Marie Claire 36, 21/10/38, p.32). Exoticism makes it possible to leave ordinary. Consequently, exoticism is related to leisure, feast, sensuality and sensuousness.

\section{b) Travelling during a dinner}

The consumption of exotic food is also seducing because it makes possible to travel during a meal, creating during a dinner the mood of holidays and travelling abroad, a way of anticipating the pleasure of the trip to come or a way to call memories of the holidays (Régnier, 2005; also see Chiva, 1993). Culinary exoticism is in consequence a way to discover foreign countries, on the contrary of regional foods which are a way to discover the treasures of the French practices (Csergo, 1996). Thus, the consumer will be transported on the road of the Indies thanks to the Indian meal. Cooking exotic product is then a form of tourism all the more easy to achieve that the cook, in search of remote horizons and other cultures, remains in her kitchen.

The consumer of exotic food can also travel through time, thanks to a kind "of historical exoticism" (Verdier, 1979, p.277) which is only anecdotic, but which mobilizes pleasant images, which increase the effect of exoticism. The reader will learn as well as the Mexican tamalès - corn sheets stuffed with meat - had allured, at the beginning of the 16th century, Cortez the conqueror, in a singular inversion where the conqueror is conquered by the culinary innovation.

Finally, consumption of exotic food is a trip through in the words which create exoticism because the simple name of a dish, and not its composition, can be enough to create the difference and the geographical distance. The terms in foreign language, often employed by the magazines, create the dream and increase the effect of exoticism. One will remember Lévi-Strauss said: a food should not only be good to eat, but also good to think. The terms in 
foreign language increase the effect of exoticism and they make dream, by the mystery which they introduce, by their play on sonorities.

\section{c) Discovering new practices}

Cooking new products is also a way to discover new culinary practices, while remaining in its kitchen, to discover new countries : "We will make you discover the Gulf of Genoa and its gastronomy this summer " proposed Marie Claire (443, 07/89, p.139), who proposes to reveal still unknown and ignored culinary treasures.

Women's magazines evoke rules of preparation and tasting. A Swedish buffet, for example, " must be very abundantly furnished. It is necessary to taste the dishes according to a rigorous order (...) Between each dish, (...) eat a steamed potato " (Marie Claire 220, 12/70: 59). The use of the two words of injunction, " duty " and " to be necessary ", as well as the recourse to the requirement, suggest many rules to be followed if one wants to be faithful to the tradition of origin.

The simplification and the codification of the foreign foods does not prevent the search for a certain authenticity and when we study culinary exoticism over a long period, we discover that the exotic recipes become more respectful from the original practices. In France, culinary exoticism was conceived for long time from a national point of view; for example, until the years 1980, the Italian recipes came from "Italy", which is conceived globally. Progressively, with the diffusion of Italian exoticism, in particular from the 1980s, several Italian regional foods appear (Tuscany, Venetian, Milanese etc), which testifies to an interest for the regional food habits of Italy. In the same way, the exotic foods are refined and specified progressively with their diffusion, allowing the integration of new products. For example, in the years 1930, the characteristic spice of West-Indian food is the curry (which is in fact not specifically West-Indian), and the colombo - which is a specifically West-Indian spice - appears finally, at the end of 1950's, illustrating a greater conformity with what is really consumed in the French West Indies.

Consequently, foreign foods are a way to improve national cooking, especially because they push consumers to eat unknown products. The food repertory of consumers increases through to the consumption of foreign foods.

\section{d) Good for health}

Finally, exotic foods are indeed conceived as good for health and the exotic products are perceived like having significant therapeutic virtues, another specificity which helps consumers to eat new products. The link established between food and health is inherent to eating : by the incorporation of a foodstuff, the consumer eats its properties, in particular its virtues, real or imaginary, when the food is regarded as positive. The eater indeed, also incorporates the symbol of this foodstuff, in relation to the magic thought of incorporation and contagion (Frazer, 1911-1915). Exotic products are regarded as particularly good for health. Very ancient representations point out the strong correlation established between the mystery of a product and its therapeutic virtues, related to the degree of social prestige of a food or a cooking. The medicinal capacity of the exotic products relies on their strangeness and their scarcity; consequently, it also relays on their prestige, obviously in relation to social distinctions. In the medieval culture, spices, to which so many virtues were lend, were also symbols of luxury. Consequently, they are consumed: "History shows that in a great number of cases, the medicinal virtues lent to a product justify its use. Then this medicine penetrates the menus " [ Fischler, 1990, p.165 ].

During the 20th century, two categories of exotic products are regarded as particularly good for health: spices, which have the global power to stimulate the body, and fruits which them is beneficial by the vitamins that they contain and by the slimming capacities of some 
(for example the " pineapple " diet or the Hollywood diet based on the consumption of varied exotic fruits). Then, two exotic foods are thought as particularly good for health, and constitute true diets : recipes of Southern Europe (considered to be particularly healthy because of the balanced nature of the meals) and recipes of Far East, particularly useful in the fight against overweight, obesity and heart conditions.

\section{Conclusion}

The consumption of new foodstuffs take place in a particular national context, revealing the influence of the history of gastronomy, colonial history and flows of food products, immigration flows and tourist migrations in the introduction of foreign foods.

But the consumption of badly known foods is not easy. In consequence, various processes help to introduce foreign culinary practices. First of all, those which aim at replacing these foreign culinary practices within a familiar framework: strategies of substitution; processes of selection and recombining foreign practices, establishing a proximity between our food habits and foreign ones, in short, making edible what is unknown. It is through this assimilation of the unknown to us (Lévi-Strauss, 1962) that we can, in an almost paradoxical way, enjoy the consumption of new products. In the same time, the seduction of foreign products comes from their difference with ours : the desire of variety leads the consumer to go beyond his fear of the unknown. Consequently, it is important to keep a kind of mystery. Through exoticism, our national cooking becomes richer and, for one time, foreign habits appear better than us. The culinary innovation is then integrated all the more easy that it is related to prestigious and positive connotations and if it is neither too unknown, nor too familiar.

\section{References}

Augé M., 1989, «Aimer, manger, mourir », in Noirot Paul (dir.), 1989, L’honnête volupté. Art culinaire, art majeur, Paris, Michel de Maule, p.6-9.

Besnard Ph., Grange C., 1993, «La fin de la diffusion verticale des goûts? », in L'année sociologique, $\mathrm{n}^{\circ} 43$, p. 269-294.

Bourdieu P., 1984, «La métamorphose des goûts », in Questions de sociologie, Paris, Éditions de Minuit, p.161-172.

Brigitte (Grüner und Jahr, Hambourg) : janvier 1952 à décembre 1999.

Burda (Verlag Aenne Burda, Offenburg) : janvier 1950 à décembre 1999.

Capatti A., 1989, Le goût du nouveau. Origines de la modernité alimentaire, Paris, Albin Michel.

Carême A., 1833, L'art de la cuisine française au XIXe siècle, Paris, Payot, éd.1994.

Certeau M. de, Giard L., Mayol P., 1994, L'invention du quotidien II, Habiter, cuisiner, Paris, Gallimard.

Chiva M., 1993, «L'amateur de durian », in N'Diaye C., La gourmandise, Paris, Autrement, série Mutations, ${ }^{\circ} 140$, p.90-96.

Csergo J., 1996, «L'émergence des cuisines régionales », in Flandrin J.-L., Montanari M. (dir.), Histoire de l'alimentation, Paris, Fayard, 1996, p.823-841.

Elias N., 1939a, La civilisation des mours, Paris, Calmann Lévy, éd. 1973.

Elias N., 1939b, La dynamique de l'Occident, Paris, Calmann Lévy, éd. 1975.

Fischler Cl., 1990, L'homnivore, Paris, O. Jacob.

Flandrin J.-L., 1989, « Le lent cheminement de l'innovation alimentaire », in Piault F. (dir.), Nourritures. Plaisirs et angoisses de la fourchette, Autrement, Paris, ${ }^{\circ} 108$, pp.68-74. 
Flandrin J.-L., 1995, «L'innovation alimentaire du XIVe au XVIIIe siècle d'après les livres de cuisine », in Eizner N. (dir.), Voyage en alimentation, Paris, A.R.F. Editions, pp.1936.

Frazer J. G., 1911-1915, Le rameau d'or, Robert Laffont, Paris, 1997.

Hassoun J.-P., Raulin A., 1995, «Homo exoticus », in Bessis S. (dir.), Mille et une bouches. Cuisines et identités culturelles, Paris, Autrement, n¹54, p.119-129.

Ketcham-Wheaton B., 1984, L'office et la bouche, Paris, Calmann-Lévy.

Lévi-Strauss Cl., 1962, La pensée sauvage, Paris, Plon.

Ma Mung E., Simon G., 1990, Commerçants maghrébins et asiatiques en France, Paris, Masson.

Marie Claire (Paris) : du n ${ }^{\circ} 1,03 / 37$ au n $^{\circ} 311,08 / 44$; du n ${ }^{\circ}, 10 / 54$ au n544, 12/97. Flammarion.

Mennell S., 1987, Français et Anglais à table, du Moyen Age à nos jours, Paris,

Modes et Travaux (Paris) : du n¹, 1919 au n¹165, 12/97.

Péhaut Y., 1996, «L'invasion des produits d'outre-mer », in Flandrin J.-L., Montanari M. (dir.), Histoire de l'alimentation, Paris, Fayard, p.747-766.

Régnier F., 2003, "Spicing up the Imagination : Culinary Exoticism in France and Germany, 1930-1990", in Food and Foodways, vol. 11, n4, p. 189-214.

Régnier F., 2004, L'exotisme culinaire. Essai sur les saveurs de l'Autre, Paris, Presses Universitaires de France.

Régnier F., 2005, «Le monde au bout des fourchettes: voyage dans l'exotisme culinaire », Site de l'Observatoire Cidil des habitudes alimentaires, juin 2005. http://www.lemangeur-

ocha.com/fileadmin/Pdf_agenda_et_actus/Regnier_Exotisme_culinaire.pdf

Todorov T., 1989, Nous êt les autres. La réflexion fräçaise sur la diversité humaine, Paris, Seuil, 1989.

Verdier Y., 1979, Façons de dire, façons de faire, Paris, Gallimard, 1979.

Warde A., 1997, Consumption, Food and Taste, London, Sage Publication.

Wildt M., 1996, Vom kleinen Wohlstand. Eine Konsumgeschichte der fünfziger Jahre, Frankfurt-am-Main, Fischer Taschenbuch Verlag GmbH. 